\title{
JÚLIO DE CASTILHOS E DEODORO DA FONSECA.
}

A chamada. "Questão Militar", simples incidente transformado por inabilidade do govêrno imperial em ato de indisciplina, quando na realidade o "aviso" que proibia os militares de se manifestarem politicamente havia sido revogado por outro àviso posterior, transformou-se em questão principalmente pela exploração feita em tôrno dêle pelos republicanos e, no Rio Grande do Sul, por Júlio de Castilhos que soube tirar o máximo da atitude de Deodoro, então Presidente da Província e Comandante Militar pela segunda vez (12-10-1885 a 22-12-1886).

Cunha Matos e Sena Madureira, militares, abolicionistas ardorosos com idéias francamente republicanas, atacados por parlamentares civis, - o deputado Simplício de Rezende e o senador Franco e Sá, - por suas atitudes na imprensa do Rio de Janeiro, resolveram, alegando defender a honra da farda, revidar os ataques. Repreendidos e presos, primeiro um e depois o outro, pelo Ministro da Guerra, também civil, - o dr. Alfredo Chaves, - viram êles e seus companheiros, no fato, apôio aos "casacas", como denominavam os civis, e vitupério à farda. O Visconde de Pelotas, militar e senador pelo Rio Grande do Sul, deu franco apôio a seus camaradas, pronunciando violento discurso que foi verdadeiro convite à revolta.

"Os oficiais do exército, - dizia êle no Senado, devem ver no que acabam de sofrer seus camaradas, uma ofensa a todos êles feita". E concluia: - "O oficial que é ferido em sua honra, tem o direito imprescindivel de desagravar-se".

Advertido o nobre Visconde de que sòmente poderia fazêlo; se as leis o permitissem, retrucou:

"Eu não digo que nossas leis o permitam; estou dizendo ao nobre Ministro da Guerra o que eu entendo que deve fazer um 'militar quando é ferido em sua honra; e que fique sabendo: 0 nobre Senador por Pernambuco que 
quem está falando assim, assim procederá, sem se importar que haja lei que o vede. Eu ponho a minha honra acima de tudo".

Sena Madureira estava servindo no Rio Grande do Sul onde era comandante da Escola de Tiro quando a questão teve irí́cio, em 1886. Manuel Deodoro da Fonseca presidia interinamente a Provincia e Comandava as Armas. Júlio de Castilhos que já vinha dos bancos acadêmicos de São Paulo propagando a República, era o diretor-redator da "A Federação", fundada pelos republicanos, com circulação iniciada a $10^{\circ}$ de janeiro de 1884.

A 30 de setembro de 1886 reuniram-se os oficiais da guarnição de Pôrto Alegre nos salões da sociedade "Soirée Pôrto Alegrense". Dessa reunião, que havia sido proibida pelo Ministro da Guerra, resultou o ptimeiro protesto e apôio aos oficiais presos, coronéis Cunha Matos e Sena Madureira, sob as vistas benévolas de Deodoro. Essa atitude do Comandante das Armas e Presidente da Província foi acolhida com júbilo pelos propagandistas, repercutindo no Rio de Janeiro, tanto na imprensa, como na Câmara, no Senado e no seio do próprio Govêrno.

A 6 de outubro de 1886 endereçava Júlio de Castilhos a seguinte carta a Deodoro da Fonseca, por incumbência de Saldanha Marinho:

"Pôrto Alegre, 6-10-1886. - Ilmo. e Exmo. Marechal Manuel Deodoro da Fonseca. - Saúdo mui respeitosamente a v. ex. - Permita-me desempenhar de uma incumbência honrosa. Acabo de receber um telegrama do conselheiro Saldanha Marinho, incumbindo-me de transmitir a v. ex. em nome dêle, as mais sinceras felicitações pela atitude nobre e correta que v. ex. assumiu na questão militar que presentemente se debate. Associando-me a essa expontânea manifestação de aprêço da parte daquele ilustre compatriota, peço a v. ex. para considerar como a expressão sincera do meu respeito e da minha admiração o que na Federação tenho tido o prazer de escrever acêrca da honrosíssima atitude de v. ex., uma das mais legítimas glórias. Às ordens de v. ex. muito atento admirador e humilde compatriota - Júlio de Castilhos".

Refere-se, aí, Castilhos, aos noticiários e editoriais de "A Federação". relativos ao caso, e à exploração do fato, devendo salientar-se o editorial - "Arbítrio e Inépcia". 
No Rio de Janeiro a questão se avolumava. A 10 de outubro fizeram os militares grande reunião: e, nela, segundo noticiário dos jornais, o conselheiro Amaral teria declarado que recebera do general Deodoro (aliás ainda coronel naquele tempo) telegrama de apôio à atitude do govêrno, portanto do Ministro do Guerra, dr. Alfredo Chaves.

A notícia foi veiculadà em Pôrto Alegre a 21, ou 20 segundo cutros. Parece, entretanto, que foi a 21 , pois no dia 20 , à noite, reuniram-se novamente os militares nos salões da sociedade "Soirée Pôrto Alegrense" e não trataram do assunto. Dessa reunião assim fala a "A Federação" de 21 de outubro de 86:

"Como constava do convite publicado nesta fôlha, reuniu-se ontem nos salões da Soirée Pôrto Alegrense, tôda a classe militar presente nesta capital. Foi assinada a dedicatória do álbum que vai ser oferecido ao distintíssimo tenente-coronel Madureira. - Tomaram-se diversas resoluções que não são conhecidas".

No mesmo jornal, número relativo ao dia 22, aparece publicado um "Protesto", cuja primeira assinatura é a do marechal Visconde de Pelotas. A estas, por ordem de pôsto, seguem-se outras, entre as quais a do coronel Manuel Deodoro da Fonseca, sendo a última à de um alferes-aluno.

Ainda, no mesmo número, apareceu a seguinte nota:

\section{"Secção Livre.}

A Reforma e o Jornal do Comércio, em referência à reunião militar havida na Côrte no dia 10 do corrente mês, publicam que o sr. conselheiro coronel Amaral declarara nessa reunião que recebera um telegrama meu, em que me congratulava com o govêrno. - Declaro que é inexato o fatôt noticiado pelo sr. conselhèiro Amaral, e autorizo a quem quer que seja a pedir na respectiva estação os telegramas por mim dirigidos a meu irmão o general Severino e ao mesmo sr. conselheiro. - M. Deodoro da Fonseca. - 22 de outubro de 1886".

Júlio de Castilhos publicoú em destaque a nota acima na "A Federação" de 22 de outubro, e fê-la preceder, também com destaque, da seguinte Declaração, de sua autoria:

"No lugar competente publicamos hoje uma honrosa declaração firmada pelo ilustre sr. general Deodoro. $O$ eminente general declara que não é exato que s. ex. se tivesse dirigido por telegrama ao seu digno irmão o sr. general Severino nos têrmos de que fêz menção o 
conselheiro Amaral perante a reunião militar efetuada no Rio de Janeiro, no dia 10 do corrente mês. - $O$ alto valor moral dessa declaraçẩo dispensa-nos de acrescentar qualquer palavra em louvor ao ilustre e prestigioso general Deodoro".

E ao Comandante das Armas e Presidente Provincial, logo que recebeu a nota que publicou em "Secção Livre", escreveu a sf.guinte carta:

"Pôrto Alegre, 22 de outubro de 1886. - Ilmo. e Exmo. sr. marechal Deodoro da Fonseca. - Saúdo respeitosamente a v. ex. - Recebi sinceramente penhorado a excelente obra que $v$. ex. teve a suma bondade de oferecer-me, devida à ilustração e ao labor do. ilustre dr. João Severiano da Fonseca. Ėsse oferecimento constitui para mim uma distinção especial que me concede v. ex. a quem sou particularmente grato. Terei ocasião de significar pessoalmente os meus agradecimentos.

A nobre declaração que v. ex. me enviou para ser publicada na Federação, terá publicidade hoje mesmo. Permita a v. ex. que a Federação se contente com a honra da preferência, pelo que peço licença para devolver a quantia que acompanhou o original da declaração.

Pede e espera sempre as ordens de v. ex. quem é muito atento e humilde servo, - Júlio de Castilhos".

(Note-se a insistência com que Castilhos denomina "marechal" ao general Deodoro que, aliás, no noticiário é, sempre, designado com o verdadeiro pôsto - coronel, a princípio e, por fim, general).

Cheia está "A Federação" de telegramas de todos os recantọs do Rio Grande do Sul e do Brasil, de apôio e congratulaçöes com Pelotas, Castilhos e Deodoro. E tôdas ou, pelo menos, em grande maioria, de militares. Entre êsses merece referência especial o endereçado ao Visconde de Pelotas pela oficialidade dô 5: Batalhão:

"Os Oficiais do 5. Batalhão fecilitam v. ex. pela atitude tomada em prol da classe militar".

E "A Federação", pela pena de Castilhos, que desde o início. vinha explorando a questão, continuou com mais violência quando o caso surgiu em Pôrto Alegre depois da reunião de 30 de setembro. Castilhos, político sagaz e hábil jornalista, tudo aproveitava, mesmo torcendo certos pormenores, a fim de melhor influir no povo e obter as simpatias dos militares. 
Foi, a nosso ver, justamente essa "questão" e sua manhosa e oportuna exploração por Castilhos, que precipitou a proclamação da República, pois no Rio de Janeiro e em São Paulo o órgão republicano de Pôrto Alegre era popularíssimo e acatado.

Deodoro, por tudo quanto permitiu e fêz, foi transferido para Mato Grosso como castigo à sua petulância, embora aparentemente constasse como simples rotina de serviço. Mas o povo sabia muito bem o que aquilo representava e tanto mais que a imprensa continuava a bater no mesmo assunto e "A Federação" dizendo, por tal motivo, "cobras e lagartos", - conforme a expressão de "O Século", de Miguel de Werna de Castro e Bilstein, explicando uma ilustração de página inteira, - do govêrno e de seus auxiliares ministeriais. E tal foi a campanha que, afinal, conseguiram o retôrno de Deodoro para o Rio de J̃neiro, onde o cercaram os amigos, companheiros políticos e ruilitares, obrigando-o a proclamar a República a 15 de novembro de 1889.

Dizemos "obrigando" porque há depoimentos valiosos que dizem ter sido Deodoro contrário ao ato pois, devendo favores a D. Pedro II, não desejava ser ingrato. Queria a República, sim, ras quando D. Pedro falecesse. Era êsse, aliás, o pensamento da maioria dos republicanos, inclusive da "Moção" famosa de Aparício Mariense da Silva. Entretanto, consumado o fato, apareceram por aí, vibrantes, ostentando, acalcanhadamente, o título de "históricos", centenas de "eminentes" que puseram à margem verdadeiros idealistas como Silva Jardim e, para sòmente citar mais um, o dr. Licínio Atanásio Cardoso, filho de nossa Lavras do Sul, que foi o autor do "Manifesto" publicado a 15 de novembro, e do qual muitos se declararam autores... 